\title{
La participación económica de los socios en las empresas cooperativas mexicanas
}

\author{
(The economic participation of members \\ in the Mexican cooperative companies)
}

\author{
Martha E. Izquierdo Muciño1 \\ Universidad Autónoma del Estado de México (México)
}

Sumario: 1. Introducción. 2. Principios cooperativos y sus implicaciones económicas. 3. Deberes y derechos de los socios y causas de exclusión. 4. De las aportaciones de los socios 5. De los certificados de aportación. 6. De los fondos sociales, 7. Retiro voluntario. 8. Conclusión. 9. Bibliografia.

Summary: 1. Introduction. 2. Cooperative principles and their economic implications. 3. Duties and rights of the members and causes of exclusion. 4. About the contributions of the members. 5. About the certificates of contribution. 6. About the social funds, 7. Voluntary withdrawal. 8. Conclusion. 9. Bibliography.

Resumen: El tercer principio cooperativo es uno de los más importantes de los reconocidos por la Alianza Cooperativa Internacional, toda vez que habla del capital social y la forma como debe integrarse a través de los socios, describe la manera como éstos deben invertir en su cooperativa y como deben distribuir sus excedentes, reforzando con ello la necesidad y el deber de que los miembros contribuyan con capital para su propio negocio y además lo hagan con justicia y equidad.

Sin embargo se observa que actualmente en muchos países las empresas cooperativas se abren cada vez más al mercado, ampliando el margen de sus operaciones con capital de riesgo e incorporando la participación de inversores no usuarios o no socios al capital social de las empresas, llegando en ocasiones a permitir que la distribución de resultados se haga en función de las aportaciones económicas y no por el ejercicio de la actividad cooperativizada, violándose con ello los principios de igualdad, equidad y solidaridad.

Palabras clave: participación económica de los socios, principios cooperativos, inversores no usuarios.

1 Catedrática e investigadora de la Universidad Autónoma del Estado de México. (UAEM), adscrita al Sistema Nacional de Investigadores (nivel 1).Especialista en el área de Derecho Social. Email: meizquierdom@uaemex.mx 
Abstract: The third cooperative principle is one of the most important of those recognized by the International Cooperative Alliance, since it talks about social capital and how it should be integrated through the members, describes how they should invest in their cooperative and how they must distribute their surpluses, thereby reinforcing the need and duty of members to contribute capital for their own business and also do so with fairness and equity.

However, it is observed that in many countries cooperative companies are increasingly open to the market, expanding the margin of their operations with risk capital and incorporating the participation of non-users or non-members to the social capital of the companies, reaching occasions to allow that the distribution of results be made in function of the economic contributions and not by the exercise of the cooperative activity, violating with it the principles of equality, equity and solidarity.

Keywords: economic participation of members, cooperative principles, investors not users. 


\section{Introducción}

El capital social de las empresas cooperativas está constituido por las aportaciones de cada uno de los socios tanto por los títulos obligatorios, como por los títulos voluntarios, y por las aportaciones de los asociados, colaboradores o figuras similares, es un instrumento fundamental para el buen funcionamiento y desarrollo de la empresa cooperativa, constituyendo una obligación inicial para cada socio.

Los socios aportan equitativamente y democráticamente el capital de su cooperativa, reforzando el deber de contribuir económicamente para su propio negocio. Esta actividad se encuadra como uno de los principios más importantes del cooperativismo en el mundo, principios que fueron ratificados por la Alianza Cooperativa Internacional en el año 1995 (Eguía 2003, 49).

Sin embargo la participación de los socios en el capital social de la cooperativa es distinta a la de las sociedades anónimas, en virtud de que el derecho de los miembros en éstas no se mide por su participación en la empresa como lo hacen las empresas cooperativas y sus características financieras son totalmente diferentes. En las empresas cooperativas, si bien el capital es un recurso necesario tiene características muy peculiares, como es la naturaleza misma de la remuneración al capital social.

En efecto, en las cooperativas el capital es un instrumento necesario pero subordinado al trabajo del socio o a su participación en las actividades de la cooperativa, el pago de intereses es voluntario y en caso de que se decida el pago este será limitado sin que se hable de dividendos o participación en resultados o excedentes netos.

El capital es acreedor, en estas sociedades cooperativas y los beneficios se atribuyen a los participantes de la actividad cooperativizada, aun cuando la retribución al capital aparezca delimitada por vía legal con criterios muy restrictivos (Gómez 2018, 04).

La Ley General de Sociedades Cooperativas (LGSC) en México ratifica estos conceptos y establece que cada socio debe aportar por lo menos el valor de un certificado, aunque también se puede pactar la suscripción de certificados excedentes o voluntarios por los cuales se percibirá el interés que fije el Consejo de Administración de acuerdo con las posibilidades económicas de la misma cooperativa y tomando como referencia las tasas que determinen los bancos para depósitos a plazo fijo (LGSC. Artículo 51. Título II. Capítulo IV).

Sin embargo actualmente se observa que un considerable número de países han aceptado la existencia de un nuevo tipo de terceros no usuarios. Se trata de inversores que no están en disposición de usar los 
servicios que prestan las cooperativas y simplemente invierten ventajosamente en ellas sus recursos financieros aumentando peligrosamente el porcentaje de capital social en manos de los mismos y llegando en algunas ocasiones a permitir que la distribución de resultados se haga en función de dicha aportación y no por el ejercicio de la actividad cooperativizada (Fernández 2017, 1-6).

Esta situación rompe desde luego con los principios de igualdad, equidad, solidaridad, pues estos se fundan en el esfuerzo propio y en la ayuda mutua debiendo utilizar la prestación de los servicios para satisfacer las necesidades de todos y cada uno de sus miembros.

\section{Principios cooperativos y sus implicaciones económicas}

El artículo 2 de la Ley General de Sociedades Cooperativas (LGSC) en México menciona que la sociedad cooperativa es una forma de organización social, integrada por personas físicas con base en intereses comunes y en los principios de solidaridad, esfuerzo propio y ayuda mutua, con el propósito de satisfacer necesidades individuales y colectivas a través de la realización de actividades económicas de producción, distribución y consumo de bienes y servicios.

Como puede observarse el objeto de una sociedad cooperativa como el de cualquier otra sociedad consiste en el ejercicio común de una actividad económica y por tanto debe actuar conforme a los mismos principios económicos de cualquier empresa, dado que su actuación se desarrolla dentro y para el mercado y en lo único que se diferencia de las demás de acuerdo a la Alianza Cooperativa Internacional es en los principios cooperativos como son:

- Primer principio: libertad de asociación y retiro voluntario de los socios.

- Segundo principio: administración democrática.

- Tercer principio: Participación económica de los socios.

- Cuarto principio: Autonomía e independencia.

- Quinto principio: fomento a la educación cooperativa y de la educación en la economía solidaria.

- Sexto principio: Participación en la integración cooperativa.

- Séptimo principio: Interés por la comunidad. (Principios cooperativos 2011, 1-3).

El tercer principio cooperativo es uno de los más importantes, toda vez que habla del capital social y la forma como debe integrarse a través de los socios. Eguia Villaseñor sostiene al respecto que las coopera- 
tivas deben funcionar de tal manera que el capital funja como servidor y no como amo. Que su finalidad sea la de satisfacer las necesidades de la gente conscientes de que este principio describe la manera como los asociados invierten en su cooperativa y la manera como deciden distribuir sus excedentes. Ratifica y refuerza la necesidad y el deber de que los miembros contribuyan con capital para su propio negocio y además lo hagan con justicia y equidad (Eguía 2003, 50).

Por su parte los autores Gómez Aparicio y Miranda García sostienen que todos estos principios cooperativos tienen implicaciones económicas como a continuación se describe:

\section{Primer principio}

Adhesión voluntaria y abierta, tiene repercusión económica al intervenir en las características del capital social toda vez que mediante las aportaciones obligatorias se obtiene jurídicamente la condición de socio. De hecho se observa que en muchas legislaciones se configura el capital social como variable por la entrada y salida de socios.

El capital social viene a ser una partida de duración limitada, exigible con la marcha del socio independientemente que su devolución se halla establecido en un determinado plazo o que sobre esas cantidades se efectué algún tipo de penalización. Estas características diferencian al capital social del resto de las sociedades capitalistas.

\section{Segundo principio}

Gestión democrática por parte de los socios. Su repercusión económica es en forma indirecta en la medida que no existe el incentivo del mayor control para mayores aportaciones a capital de los socios.

\section{Tercer principio}

Participación económica de los socios. Su repercusión económica será en la medida que se establezca que las aportaciones financieras serán las mismas para todos los socios y no solo se considere la mayor capacidad financiera de algunos de ellos.

Por otra parte el capital al menos una parte será propiedad común de la cooperativa, toda vez que con ello habrán de formarse las reservas. 
Las aportaciones al capital social normalmente reciben una retribución limitada y en la medida que la retribución es limitada la motivación para efectuar estas aportaciones también será limitada.

Sin embargo se pueden repartir entre los socios los excedentes, en la medida que han contribuido para generarlos, esto es función a su contribución a los procesos de las aportaciones al capital social efectuados.

\section{Cuarto principio}

Autonomía e independencia, este principio enuncia que las cooperativas son organizaciones autónomas gestionadas por sus socios y que si llegan a firmar acuerdos con otras organizaciones $u$ organismos (incluyendo al Estado) para conseguir capital de fuentes externas, deben hacerlo en términos que aseguren el control democrático por parte de sus socios para poder seguir manteniendo la autonomía.

\section{Quinto principio}

Educación, formación e información en algunas legislaciones como en la mexicana existe la obligatoriedad de dotar una reserva legar destinada a este fin, con un tratamiento económico peculiar a fin de proporcionar educación y formación a sus socios y empleados.

\section{Sexto principio}

Cooperación entre cooperativas. La finalidad es que las cooperativas sirvan a sus miembros lo mejor posible y se fortalezca el movimiento cooperativo trabajando conjuntamente a nivel local, nacional e internacional ya que al favorecerse la Intercooperación las empresas se favorecen económica y fiscalmente.

\section{Séptimo principio}

Interés por la comunidad. Este principio aun cuando no se representa en forma económica, evidentemente hace alusión a las ventajas económicas que las sociedades cooperativas difunden en su entorno, derivados de la estrecha vinculación del medio donde operan (Gómez 2018, 4-26). 


\section{Deberes y derechos de los socios y causas de exclusión}

La participación de los socios en la cooperativa es un derecho y una obligación, pues de ello depende en gran parte que la cooperativa sea exitosa.

Es a través de la participación de los socios que la cooperativa pueda enriquecerse, ya que únicamente con socios comprometidos y cooperadores es como una cooperativa puede crecer.

Al pertenecer a una sociedad cooperativa se adquieren derechos y obligaciones, los cuales en la legislación cooperativa mexicana se determinan en los artículos 64 y 65 (LGSC) y en las bases constitutivas de la misma.

Entre los principales derechos se encuentran:

- Tener voz y voto en la Asamblea General (un hombre un voto).

- Elegir mediante su voto a las autoridades de la cooperativa.

- Solicitar y recibir informes de las autoridades de la cooperativa.

- Recibir estímulos cuando cumplen con sus obligaciones.

- El derecho a pertenecer al partido político o asociación religiosa que mejor le parezca.

- Recibir un rendimiento anual, en caso de que existiera un excedente.

- Derecho al retiro voluntario en el momento que lo desee (Repetto 2000, 49).

Se consideran obligaciones de los socios los siguientes:

- La obligación de consumir o de utilizar los servicios que las sociedades cooperativas de consumidores brinden a sus socios.

- En las sociedades cooperativas de productores la prestación del trabajo personal de los socios podrá ser físico, intelectual o de ambos géneros.

- Las sanciones a los socios de las sociedades cooperativas cuando no concurran a las asambleas generales, juntas o reuniones que establece la presente Ley; éstas deberán considerar las responsabilidades y actividades propias de la mujer.

- Las sanciones contra la falta de honestidad de socios y dirigentes en su conducta con el manejo de fondos que se les hayan encomendado.

— Los estímulos a los socios que cumplan cabalmente con sus obligaciones.

- La oportunidad de ingreso a las mujeres, en particular a las que tengan bajo su responsabilidad a una familia (Repetto 2000, 53). 
Se considera importante destacar el hecho de que en las sociedades cooperativas de producción se puede contar con personal asalariado aunque con ciertas limitaciones como en los siguientes casos:

- Únicamente cuando las circunstancias extraordinarias o imprevistas de la producción o los servicios lo exijan.

- Para la ejecución de obras determinadas.

- Para trabajos eventuales o por tiempo determinado o indeterminado, distintos a los requeridos por el objeto social de la sociedad cooperativa.

- Para la situación temporal de un socio hasta por seis meses en un año.

- Por la necesidad de incorporar personal especializado altamente calificado (LGSC, artículo 65, Título II capítulo V).

Respecto a las causas de exclusión el artículo 38 de la LGSC, menciona que serán causas de exclusión las siguientes:

- Desempeñar sus labores sin la intensidad y calidad requeridas.

- Falta de cumplimiento en forma reiterada a cualquiera de sus obligaciones establecidas en las bases constitutivas sin causa justificada.

- Infringir en forma reiterada las disposiciones de esta ley, de las bases constitutivas o del Reglamento de la sociedad cooperativa. De las Resoluciones de la Asamblea General o de los acuerdos del Consejo de Administración de sus gerentes comisionados.

\section{De las aportaciones de los socios}

El tercer principio cooperativo regula la participación económica de los socios pues éstos contribuyen en forma equitativa al capital social de su empresa y lo gestionan democráticamente. Parte de ese capital es propiedad común de la cooperativa. Los socios reciben generalmente una retribución limitada sobre el capital aportado y asignan los excedentes para el desarrollo de su cooperativa a través de las reservas que se constituyen de las cuales una parte será irrepartible.

Eguía Villaseñor menciona que el capital es necesario para realizar el objeto final de la cooperativa, esto es el fin para el cual fue creada y por ello se considera más valiosa que cualquier otra asociación dado que primero es la persona y después lo demás. Primero es la asociación como base y luego su cristalización como es el negocio (Eguía 2002, 138). 
En el capítulo cuarto de la LGSC en México, se habla del régimen económico en donde se menciona la forma como puede integrarse el capital de una sociedad cooperativa, que es con las aportaciones de los socios y la manera como pueden hacerse dichas aportaciones. Menciona además que serán por lo menos el equivalente al valor de un certificado. Asimismo menciona la posibilidad de pactarse la suscripción de certificados excedentes o voluntarios por los cuales habrá de percibirse el interés que fije el Consejo de Administración de acuerdo con las posibilidades económicas de la sociedad cooperativa tomando como referencia las tasas que determinen los bancos para depósitos a plazo fijo (LGSC, artículo 51, título II, capítulo IV).

Del excedente será la Asamblea quien juzgue la manera como habrá de hacerse la devolución a los socios, así como también vigilara las formas como habrán de constituirse los Fondos Sociales como son: los Fondos de Reserva, de Previsión y de Educación cooperativa etc.

Menciona dicha ley que las aportaciones podrán hacerse en efectivo, bienes, derechos o trabajo y estarán representadas por certificados que serán nominativos, individuales y de igual valor, los cuales deberán actualizarse anualmente (LGSC, artículo 50, título II, capítulo IV).

En el caso de que existan aportaciones que no sean en efectivo la valorización de las mismas se hará en las bases constitutivas al momento de ingresar el socio por acuerdo de éste y por el Consejo de Administración con la aprobación de la Asamblea General.

Sin embargo al momento de constituirse una sociedad cooperativa o al ingresar el socio a ella será obligatoria la exhibición del 10\% cuando menos del valor de los certificados de aportación.

Ahora bien cuando la Asamblea General acuerde reducir el capital que juzgue excedente la devolución se hará a los socios que posean mayor número de certificados de aportación o prorrata si todos son poseedores de un número igual de certificados. Sin embargo si se trata de aumentar el capital todos los socios estarán obligados a suscribir el aumento en forma y términos que acuerde la Asamblea General (LGSC, artículo 52, Título II. Capítulo IV).

Bajo esta tónica considera la conocida autora Alicia Kaplan que durante el compromiso de disponer de recursos financieros para el cumplimiento de sus objetivos las cooperativas contaron tradicionalmente con aportes económicos realizados por sus miembros, de tal suerte que los socios tenían el triple carácter de propietarios, de encargados de la administración y de utilizadores de los servicios de dichas empresas.

Asimismo se respetaron siempre los principios cooperativos al reconocer a cada miembro un solo voto en las cooperativas primarias cualquiera que fuera el monto de sus aportaciones, se estableció además 
que los excedentes solo podrían distribuirse entre los miembros en proporción a sus respectivas operaciones con la empresa.

Las disposiciones legislativas o estatutarias relacionadas con las aportaciones de los miembros se establecieron siempre bajo los principios cooperativos de igualdad, equidad y solidaridad, no obstante ello se observa que actualmente las necesidades financieras que han experimentado las empresas cooperativas en los últimos años, las han inducido a aceptar aportes financieros que las apartan de los rasgos tradicionales pues existe cierta renuncia a la igualdad de derechos y deberes de los titulares de las acciones cuando se autoriza la emisión de acciones sin derecho a voto o bajo ciertas condiciones especiales (Kaplan 1997, 103).

Por otra parte existe renuncia al sistema tradicional de distribución de excedentes en proporción en las actividades realizadas por cada socio con su cooperativa cuando se autoriza a estos a distribuir hasta la mitad de sus excedentes sobre la base del capital accionario de los miembros y finalmente existe renuncia de concepto tradicional de propiedad, de administración y de utilización de la cooperativa cuando se admiten miembros inversores no usuarios.

A mayor abundamiento existen datos que nos demuestran que un considerable número de países ha aceptado la existencia de un nuevo tipo de socios; los miembros inversores no usuarios que coinciden con las siglas en inglés N.U.I.M. o en español M.I.N.U., se tratan de inversores que no están en disposición de usar los servicios que prestan las cooperativas y simplemente invierten ventajosamente en ellos sus recursos financieros.

De hecho se observa que este tipo de inversores han logrado facultades de miembros sin derecho al voto o bien han pasado en algunos países a disponer de un considerable parte de votos de las asambleas así como a disponer de crecientes poderes de administración en estas empresas (Izquierdo 2017,37).

Por su parte Josefina Fernández, de la Universidad Complutense menciona que asistimos a un proceso de descoperativización en el que se encuentran numerosas empresas cooperativas, situación que se ha visto favorecida en muchos países por la propia legislación cooperativa dando entrada a nuevos elementos que distancian la identidad y la práctica cooperativa.

Cita que en diversos países de la Unión Europea se han introducido nuevas formas de movilización de recursos financieros, incorporando la participación de inversores no usuarios ó no socios en el capital social aun cuando se establezcan ciertos límites. Esta situación aumenta peligrosamente el porcentaje de capital social en manos de terceros que no son socios llegando a permitir en algunos casos que la distribución 
de resultados se haga en función de la aportación y no por el ejercicio de la actividad cooperativizada como establece la Alianza Cooperativa Internacional en el tercer principio cooperativo de participación económica (Fernández 20017, 1-5).

Además se rompe con los demás principios cooperativos de igualdad, equidad, solidaridad, pues como hemos mencionado estos se fundan en el esfuerzo propio y en la ayuda mutua, utilizando la prestación de los servicios para satisfacer las necesidades de todos y cada uno de sus miembros.

Afirma dicha autora que existe una gran contradicción con los principios de carácter cooperativo dada la distribución de excedentes en proporción con las operaciones de los miembros y de no otorgar ventajas o privilegios a los socios y mucho menos a parte del capital ocasionando con ello la posibilidad de que los miembros inversores no usuarios conduzcan a la preeminencia de actos sobre los demás socios de la empresa ya que con ello se corre el riesgo de un deslizamiento hacia formas capitalistas (Fernández 2017, 3-6).

Lo cierto es que el ejercicio de los derechos políticos y económicos de estas sociedades capitalistas introducen un elemento de conflicto por la diversidad de intereses entre estos y los socios cooperadores que participan en la actividad empresarial dada la creciente tendencia del aumento de poderes de los gerentes y administradores que podría complicar aún más la relación con los inversores no usuarios.

\section{De los certificados de aportación}

Resulta conveniente señalar el ámbito de actuación económica de las sociedades cooperativas en México toda vez que la ley actual a diferencia de las anteriores leyes que han existido en lugar de declarar que las sociedades no fuesen lucrativas o especulativas, la Ley General de Sociedades Cooperativas de 1994 estimó conveniente dejarse manejar sin limitar su participación de manera discriminatoria con respecto a otras figuras especialmente por lo que toca a sus oportunidades de acumulación y desarrollo. Asimismo se estimó conveniente que pudieran participar en todos los campos de la economía en que se desarrollan sin limitación alguna en la totalidad del ciclo económico y además que tuvieran acceso al financiamiento externo con respaldo de fondos de garantía (Izquierdo 2003, 237).

En efecto la Ley General de Sociedades Cooperativas de 1994 actualmente vigente, menciona que se podrán dedicar libremente a cualquier actividad económica siendo lícita. Su forma de clasificación es: de 
consumidores de bienes y/o servicios, y de Productores de bienes y/o servicios, de ahorro y préstamo (LGSC, Artículo 21, Título II, capítulo II).

Dicha ley menciona entre otras cosas que podrán emitirse certificados de aportación para capital de riesgo por tiempo determinado (LGSC, Artículo 63, Título II, Capítulo IV). Asimismo menciona que la Secretaría de Hacienda y Crédito Público deberá de común acuerdo con el Consejo Superior del Cooperativismo, con las Confederaciones, Federaciones y Uniones, podrán constituir fondos de garantía de origen federal, que apoyarán a las sociedades cooperativas en su acceso al crédito, mediante el otorgamiento de garantías que cubran el riesgo del proyecto de inversión. (LGSC, artículo 94, Título IV, Capítulo Único), a continuación se presenta el siguiente cuadro:

\begin{tabular}{l|l|l|l}
\hline $\begin{array}{c}\text { Ley General } \\
\text { de Sociedades } \\
\text { Cooperativas 1927 }\end{array}$ & $\begin{array}{c}\text { Ley General } \\
\text { de Sociedades } \\
\text { Cooperativas 1933 }\end{array}$ & $\begin{array}{c}\text { Ley General } \\
\text { de Sociedades } \\
\text { Cooperativas 1938 }\end{array}$ & $\begin{array}{c}\text { Ley General } \\
\text { de Sociedades } \\
\text { Cooperativas 1994 }\end{array}$ \\
\hline $\begin{array}{l}\text { Artículo 13 F VII } \\
\text { Artículo 19 F I }\end{array}$ & $\begin{array}{l}\text { Artículo 5, } \\
\text { Artículo 6, } \\
\text { Artículo 7, } \\
\text { Artículo 8, } \\
\text { Artículo 9 }\end{array}$ & $\begin{array}{l}\text { Artículo 1. }{ }^{\circ} \mathrm{F} \mathrm{VI,} \\
\text { Artículo 8 }\end{array}$ & $\begin{array}{l}\text { Artículo 13 F VII } \\
\text { Artículo 21, } \\
\text { Artículo 63 } \\
\text { Artículo 94 }\end{array}$ \\
$\begin{array}{l}\text { Pueden dedicarse } \\
\text { sólo a las activida- } \\
\text { des designadas. }\end{array}$ & $\begin{array}{l}\text { Pueden dedicarse } \\
\text { sólo a las activida- } \\
\text { des designadas }\end{array}$ & $\begin{array}{l}\text { Pueden dedicarse } \\
\text { sólo a las activida- } \\
\text { des designadas. }\end{array}$ & $\begin{array}{l}\text { Pueden dedicarse } \\
\text { a cualquier activi- } \\
\text { dad siendo lícita. }\end{array}$ \\
& \multicolumn{2}{c}{$\begin{array}{l}\text { No persiguen fi- } \\
\text { nes de lucro }\end{array}$} & $\begin{array}{l}\text { Tienen acceso al } \\
\text { financiamiento } \\
\text { con respaldo de } \\
\text { capital de riesgo. }\end{array}$ \\
\hline
\end{tabular}

Fuente: el cuadro es nuestro.

Los certificados de aportación para capital de riesgo son títulos emitidos por las sociedades cooperativas representativos de derechos pecuniarios relacionados con una parte del capital social.

Se argumenta que son títulos muy semejantes a las obligaciones tradicionales cuya característica principal es que son que son reembolsables mientras dura la vida de la sociedad y que son libremente negociables con posible cotización en bolsa.

Respecto a la proporción que representan respecto al capital social, se observa que pueden establecerse algunas limitaciones, aunque dicha proporción no debe disminuir. 
Los poseedores de estos certificados gozan de una remuneración equivalente a las aportaciones del capital social, así como de un derecho sobre el activo neto, resultante de la liquidación.

No participan en la vida social del a empresa aunque si en la información de cuentas.

Estos derechos no pueden ser modificados con respecto a las condiciones de la emisión sin tener previamente el acuerdo de los poseedores de éstos certificados expresado en una Asamblea General (Gómez 2018, 13-26).

Respecto a este punto simplemente se hace necesario acordar el peligro de renuncia a la igualdad de derechos y deberes de los titulares de las acciones, así como a la renuncia al sistema tradicional de excedentes en proporción a las operaciones realizadas por cada socio y a la renuncia al concepto tradicional del significado de propiedad cooperativa, la administración y la utilización de los servicios de la cooperativa, especialmente cuando se admitió a miembros que en la doctrina se les ha denominado "MINU» (miembros inversionistas no usuarios) como se ha señalado anteriormente.

En virtud de que esta situación podría traer consigo una evidente contradicción con los valores cooperativos de igualdad, equidad, solidaridad, esfuerzo propio, ayuda mutua, etc., ya que puede existir una desventaja en la distribución de los excedentes en proporción con las operaciones de los socios y las posibles ventajas del capital.

\section{De los fondos sociales}

La formación de reservas en la sociedad cooperativa tiene como objeto establecer una dotación más o menos cuantiosa de las reservas legales, las cuales son irrepartibles, al serlo forman una fuente financiera totalmente estable que brinda seguridad frente a terceros incluyendo a los mismos socios. Sin embargo y no obstante lo anterior se puede provocar un efecto contraproducente en la solvencia financiera ya que puede producir desánimo en los socios y provocar bajas pero por otra parte contribuye a la independencia económica respecto a los socios en la medida que dichos recursos pertenecen a la empresa y no a estos (Gómez 2018,13-26).

El fondo de reservas es obligatorio así como los demás fondos son irrepartibles, constituyendo unos componentes sumamente importantes dentro de la estructura financiera de la sociedad cooperativa ya que su función es procurar la solvencia financiera y con ello garantizar la supervivencia de la sociedad. 
En las sociedades cooperativas mexicanas se pueden constituir los siguientes fondos sociales:

I. De Reserva.

II. De Prevención Social, y

III. De Educación Cooperativa (LGSC, artículo 53, Título II, Capítulo IV).

El Fondo de Reserva se constituye con el 10 al 20\% de los rendimientos que obligan las sociedades cooperativas de cada ejercicio social. Este fondo puede quedar delimitado en las bases constitutivas pero no será menor del $25 \%$ del capital social en las sociedades cooperativas de productores y del $10 \%$ en las de consumidores, puede ser efectuado cuando lo requiera la sociedad para afrontar las pérdidas o bien para restituir el capital de trabajo, debiendo de ser reintegrado al final del ejercicio social. Es importante señalar también que éste fondo debe ser manejado por el Consejo de Administración con la aprobación del Consejo de Vigilancia (LGSC artículo 55, Título II, Capítulo IV).

En las sociedades cooperativas de ahorro y préstamo el fondo de reserva debe constituirse por lo menos con el 10\% de los excedentes que se obtengan en cada ejercicio social hasta alcanzar un momento equivalente a por lo menos el 10\% de los activos totales de la sociedad. Este fondo solo puede ser afectado por decisión de la Asamblea General previa decisión cuando se requiera para afrontar pérdidas o restituir al capital de trabajo, debiendo ser reintegrado en ejercicios subsecuentes (LGSC artículo 55Bis, Título II, Capítulo IV).

El Fondo de Prevención Social. Este no puede ser limitado y debe destinarse a reservas para cubrir los riesgos y enfermedades profesionales y formar fondos de pensiones y haberes de retiro de socios, primas de Antigüedad y para fines diversos que cubrirán tanto los gastos médicos y de funeral, subsidios por incapacidad, becas educacionales para los socios o sus hijos, guarderías infantiles, actividades culturales y deportivas, actividades culturales de naturaleza analógica. Sin embargo las prestaciones que deriven el fondo de Prevención Social, son independientes de las prestaciones a que tengan derecho los socios por su afiliación a los sistemas de seguridad social (LGSC artículo 57, Título II, Capítulo IV).

Por otra parte e Independientemente de las Prestaciones de Prevención Social anteriormente mencionadas las Sociedades Cooperativas en general deberán afiliar obligatoriamente a sus trabajadores y socios que aporten su trabajo personal a los sistemas de Seguridad social e instrumentar las medidas de seguridad e higiene en el trabajo, así como de capacitación y adiestramiento Toda vez que gozan del beneficio expre- 
sado en los artículos 116 y 179 de la Ley de Seguro Social, Institución de gran prestigio en nuestro país. (Repetto 1999, 34).

El fondo de Prevención Social se constituye con la aportación anual del porcentaje que sobre los ingresos netos sea determinado por la Asamblea General, pudiéndose aumentar este porcentaje según los riesgos probables y la capacidad económica de la sociedad cooperativa.

Finalmente el Fondo de Educación Cooperativa se constituye con el porcentaje, que acuerde la Asamblea General, pero en todo caso dicho porcentaje no puede ser inferior al $1 \%$ de los ingresos netos del mes. Las sociedades cooperativas pueden recibir de personas físicas y morales, públicas o privadas, nacionales e internacionales, donaciones subsidios, herencias y legados para aumentar su patrimonio (LGSC art.59 Título II, Capítulo IV).

Sin embargo un punto que resulta importante acentuar en la ley es su naturaleza social, dado que la Ley de 1994, actualmente vigente menciona que las Sociedades Cooperativas «podrán» constituir los Fondos de Reserva, de Previsión Social y de Educación Cooperativa (LGSC Artículo 53, Título II, Capítulo IV).

A continuación se presenta el siguiente cuadro:

\begin{tabular}{l|l|l|l}
\hline $\begin{array}{c}\text { Ley General de } \\
\text { Sociedad de } \\
\text { Cooperativas 1927 }\end{array}$ & $\begin{array}{c}\text { Ley General de } \\
\text { Sociedad de } \\
\text { Cooperativas 1933 }\end{array}$ & $\begin{array}{c}\text { Ley General de } \\
\text { Sociedad de } \\
\text { Cooperativas 1938 }\end{array}$ & $\begin{array}{c}\text { Ley General de } \\
\text { Sociedad de } \\
\text { Cooperativas 1994 }\end{array}$ \\
\hline Artículo 55 & $\begin{array}{l}\text { Artículo 2 F X y } \\
\text { XII }\end{array}$ & $\begin{array}{l}\text { Artículo 38, } \\
\text { Artículo 39, } \\
\text { Artículo 40 }\end{array}$ & $\begin{array}{l}\text { Artículo 53, } \\
\text { Artículo 54, } \\
\text { Artículo 55, } \\
\text { Artículo 56 }\end{array}$ \\
$\begin{array}{l}\text { Deben constituir } \\
\text { Fondos de Reser- } \\
\text { va. }\end{array}$ & $\begin{array}{l}\text { Deben constituir } \\
\text { Fondos de Reser- }\end{array}$ & $\begin{array}{l}\text { Deben constituir } \\
\text { Fondos de Reser- } \\
\text { va. }\end{array}$ & $\begin{array}{l}\text { Podrán constituir } \\
\text { Fondos de Reser- } \\
\text { va. }\end{array}$ \\
\hline
\end{tabular}

Fuente: el cuadro es nuestro.

Diversos analistas criticaron en su momento la ley actual, al disponer que estos fondos podían ser «discrecionales», mencionando que no era conveniente esta situación, ya que era importante que toda sociedad cooperativa tuviera obligatoriamente fondos de esa naturaleza, pues el de reserva servía como respaldo en caso de que la cooperativa sufriera pérdidas y con el mismo pudiera cumplir con las obligaciones contraídas (Propuesta de reformas 2000). 
Mencionaban en su momento que el fondo de previsión social también resultaba de gran trascendencia, pues está destinado a cubrir prestaciones de previsión social que son indispensables fundamentalmente en una organización en que los socios aportan su trabajo físico dado que están sujetos a sufrir riesgos de accidentes y por lo que toca al fondo de educación cooperativa opinaron que era esencial a fin de que se pudiera brindar a cada uno de los socios, la educación y capacitación para hacerlos partícipes activos en la propia empresa (Izquierdo 2003, 267).

En efecto, se hace necesario recordar que la empresa cooperativa no percibe utilidades como las empresas privadas mismas que son repartidas entre sus miembros en razón a los aportes al capital o se destina a la capitalización de la empresa, sino que en las empresas cooperativas, los excedentes que se obtienen son destinados a incrementar las reservas legales, a formar fondos de beneficio social, de educación o asignando a los miembros beneficios cooperativos en proporción como es el caso de las cooperativas de consumidores que se asignan de acuerdo al uso que los asociados hayan hecho de los servicios de la entidad, lo que significa una devolución de parte de lo pagado al hacer las adquisiciones y en el caso de las cooperativas de productores es una adición o complemento a lo inicialmente recibido por su trabajo.

Como se observa el concepto de excedentes cooperativo difiere grandemente de la idea de utilidad de la empresa capitalista, pudiendo tener la posibilidad de que el excedente pueda ser repartido entre sus miembros o bien cubrir finalidades de tipo social o cultural lo que no puede aceptarse es que estos fondos que resultan ser tan importantes tanto para los socios como para la cooperativa misma, puedan ser de carácter «discrecional».

\section{Retiro voluntario de los socios}

La LGSM en México establece que será la Asamblea General quien habrá de resolver todos los negocios y problemas de importancia para la sociedad cooperativa como es entre otras cosas: "la aceptación y separación voluntaria de socios». Por cuanto hace a las Sociedades Cooperativas de Ahorro y Préstamo en sus bases constitutivas se prevé que los socios deben solicitar el retiro de sus aportaciones y ahorros en la Sociedad en cualquier tiempo siempre y cuando no existan operaciones activas pendientes, en cuyo caso se deben liquidar previamente.

Igualmente se establece que en el caso de que varios de los socios soliciten al mismo tiempo el retiro de sus aportaciones y aho- 
rros la cooperativa fijara plazos para la entrega de sus montos de acuerdo a la disponibilidad de capital de trabajo y al índice de capitalización que mantenga la sociedad (LGSC, artículo 65 Bis, título II, Capítulo V).

Se observa que en algunos países en los casos de retiro voluntario de alguno de los socios o en el caso de liquidación y disolución de la sociedad cooperativa tradicionalmente se aplica de la siguiente manera:

Las disposiciones legales o reglamentarias vigentes en algunos países tuvieron el carácter irrepartible de esas reservas. Sin embargo se determinó que los socios que no hubieran abonado sumas suplementarias para las reservas cooperativas existentes al momento de su retiro o en el caso de su disolución y liquidación de la entidad cooperativa, se estableció que una vez que fuera devuelto el valor nominal de las acciones cooperativas integradas y satisfechas las deudas y otras obligaciones de la entidad, es cuando podría darse un destino desinteresado a las reservas constituidas.

En otros países por el contrario se admitió que los miembros que se retirarán individualmente de la entidad, podrían recibir la parte que le correspondía de las reservas existentes, reconociéndoles derechos en algunos casos sobre el total de las reservas no obligatorias. Asimismo se estableció que el remanente total de esas reservas debían distribuirse de la manera más equitativa posible entre los miembros existentes al momento de la disolución y liquidación de la entidad sobre todo en los países en donde las cooperativas no gozaban de excepciones o ventajas fiscales aun cuando se reconocieron que tal distribución de reservas no era nada común (Principio de participación 2018, 3-9).

Como es de observarse estas dos prácticas acentúan la posibilidad de que:

- Se requieran sumas adicionales a los nuevos miembros de acuerdo con las reservas cooperativas de los últimos años.

- Se reconozca la prioridad a los inversores (sean o no miembros de la sociedad cooperativa) en caso de disolución y liquidación de la cooperativa y por sobre los derechos de los socios usuarios de los servicios de la cooperativa.

- Se destine el saldo de las operaciones de revalúo del capital de las cooperativas tanto a las reservas de la entidad como a la recapitalización de sus miembros.

De tal suerte que de los cambios introducidos resulten los intereses económicos y financieros de las personas involucradas en las coopera- 
tivas minimizando los caracteres sociales y solidarios del sistema y destacando aquellos intereses pecuniarios individuales por sobre todo los intereses comunes de los socios, dando prioridad a los derechos de inversores no usuarios a quienes solo pueden interesarles el resultado financiero de sus aportaciones, olvidando el peligro que puede significar él devalúo y adjudicación en capital a las reservas de entidad, lo cual puede producir la apropiación indebida por algunos socios o inversores de las reservas acumuladas, reservas que significan el esfuerzo sostenido de generaciones precedentes (Izquierdo 2003, 278).

\section{Conclusión}

En conclusión podemos afirmar que de los principios cooperativos formulados por la Alianza Cooperativa Internacional, el tercero es uno de los más importantes ya que contiene una especial relevancia por su contribución al capital como instrumento fundamental para el buen desarrollo de la empresa.

Sin embargo es necesario evitar en lo posible en la ley General de Sociedades Cooperativas que:

- Se requieran sumas adicionales a los nuevos miembros de acuerdo con las reservas cooperativas de los últimos años.

- Que se reconozca prioridad alguna a los inversores (sean o no sean miembros de la empresa) sobre todo en los casos de disolución y liquidación de la empresa cooperativa por sobre los derechos de los socios usuarios de los servicios de la cooperativa.

- O que se destine el saldo de las operaciones de revalúo del capital de las cooperativas tanto a reservas de la entidad como a la capitalización de sus miembros ya que con ello se resaltarían los intereses económicos y financieros de las personas involucradas en las cooperativas y se minimizaran los caracteres sociales y solidarios de la misma.

Lo que significa en conclusión: que no se deben destacar los intereses pecuniarios individuales por sobre los intereses comunes, ni se debe priorizar los derechos a los inversores «no usuarios» ya que a ellos sólo puede interesarles el resultado financiero de sus operaciones, violándose con ello los principios de igualdad, equidad y solidaridad. 


\section{Bibliografía}

CAMARA REPETTO, Oswaldo y TOLOZA PAZOS, Baltazar. 2000. Marco Legal administrativo, contable y fiscal del cooperativismo. México. Grupo Empresarial Cooperativo Mexicano SCL

CAMARA REPETTO, Oswaldo y MANERO MORENO Enrique. 1999 Manual para la cooperativa de vivienda. México. Grupo Empresarial Cooperativo Mexicano, SCL.

EGUIA VILLASEÑOR, Florencio. 2002. ABC de la cooperación. 2. ${ }^{a}$ edición. México. Caja Popular Mexicana SAP y Programa del Fondo Nacional de Apoyo a Empresas Solidarias (FONAES).

EGUIA VILLASEÑOR, Florencio. 2003. Identidad Cooperativa. Alianza Cooperativa Internacional. México. Caja Popular Mexicana y Confederación mexicana de Cajas Populares.

IZQUIERDO MUCIÑO, Martha Elba. 2017. La adhesión voluntaria e identidad cooperativa en las empresas cooperativas mexicanas. Boletín de la Asociación Internacional de Derecho Cooperativo. 51: 21-45.

IZQUIERDO MUCIÑO, Martha Elba. 2003. La naturaleza de las empresas cooperativas en México. Tesis Doctoral. Universidad Nacional Autónoma de México (UNAM).

MEDINA CONDE, A. y FLORES ILHUICATZI, U. 2018. "Estudio dialéctico de la economía social». Boletín de la Asociación Internacional de Derecho Cooperativo, núm. 52, pp. 73-106. doi: http://dx.doi.org/10.18543/baidc52-2018pp73-106

KAPLAN DE DRIMER; Alicia. 1997. Mutaciones estructurales de las cooperativas. España. Ministerio del Trabajo y Asuntos Sociales y Dirección General de Fomento a la Economía Social. Ediciones CIRIEC.

\section{Legisgrafía}

LEY GENERAL DE SOCIEDADES COOPERATIVAS (Cámara de Diputados del $\mathrm{H}$. Congreso de la Unión.) Ultima Reforma publicada por el Diario Oficial de la Federación. 13.08.2009.

PROPUESTA DE REFORMAS A LA LEY GENERAL DE SOCIEDADES COOPERATIVAS. Año 2000. H. Cámara de Diputados del Congreso de la Unión.

\section{Páginas electrónicas}

ALIANZA COOPERATIVA INTERNACIONAL. Oficina para las Américas. Plan Estratégico 2000-2004. Mensaje de la Alianza Cooperativa Internacional. http/www.cudecoop.org.uy/revista/revistas/0796.html / (Consultado el 24.02.2018) 
FERNANDEZ GUADAÑO, Josefina. 2007. «Análisis de la participación de los socios inversores externos en el capital de las sociedades cooperativas en Europa». El comportamiento de la empresa ante entornos dinámicos: $X I X$ Congreso anual y XV Congreso Hispano Francés de AEDEM, Vol. 1, 2007, pp. 75 y ss. https://dialnet.unirioja.es/descarga/articulo/2480604.pdf (Consultado el 8 de abril de 2018).

GOMEZ APARICIO, Pilar y MIRANDA GARCÍA, Martha. 2006. "Sobre el régimen económico y financiero particular de las sociedades cooperativas». REVESCO, Revista de estudios cooperativos, núm. 90, pp. 28-56. http://webs. ucm.es/inforevesco/txt/REVESCO\%20N\%2090.2.\%20pilar\%GOMEZ,\%2 (Consultado el 19.02.2018).

La regulación de la participación financiera de los socios inversores en la legislación cooperativa de los países miembros de la Unión Europea. htttps://www.reserchgate.net/publicaction/28202532_analisis_de_laparticipacion_de_los_socios_inversores_externos_en_el_capital_de_las_ sociedades_cooperativas_en_europa (consultado el 08.03.2018)

Inversiones en certificados de aportación. http://www.cacebece.com/cacebece/ index.php/productoslinversiones-en-certificados-de-aportacion (Consultado el 23 03.2018).

Principio de participación económica de los socios. Federación de Cooperativas Agroindustriales.https://euskadi.coo/principio-de-participacion-economicade-los-socios (consultado el 9.03.2018).

Principios cooperativos. Documento de la Alianza Cooperativa Internacional. https://es. wikisource.org/windex.php?title=principios_ cooperativos\&oldis=499825 (Consultado el 9.03.2018). 


\section{Derechos de autor}

El Boletín de la Asociación Internacional de Derecho Cooperativo es una revista de acceso abierto lo que significa que es de libre acceso en su integridad inmediatamente después de la publicación de cada número. Se permite su lectura, la búsqueda, descarga, distribución y reutilización legal en cualquier tipo de soporte sólo para fines no comerciales y según lo previsto por la ley; sin la previa autorización de la Editorial (Universidad de Deusto) o el autor, siempre que la obra original sea debidamente citada (número, año, páginas y DOI si procede) y cualquier cambio en el original esté claramente indicado.

\section{Copyright}

The International Association of Cooperative Law Journal is an Open Access journal which means that it is free for full and immediate access, reading, search, download, distribution, and lawful reuse in any medium only for non-commercial purposes, without prior permission from the Publisher or the author; provided the original work is properly cited and any changes to the original are clearly indicated. 